\title{
O USO DAS PAUSAS NOS DIFERENTES ESTILOS DE TELEVISÃO
}

The use of pauses in different styles of TV programs

\author{
Cláudia Cotes ${ }^{(1)}$
}

\section{RESUMO}

Objetivo: investigar a distribuição e funções das pausas silenciosas no discurso oral em narrações de programas de televisão de natureza diferenciada. Métodos: para este estudo foram selecionadas amostras de fala de dois jornalistas em cinco programas de televisão. As medidas foram embasadas na análise fonético-acústica, segmentando-se os tempos de narração e de pausas silenciosas em milisegundos (ms) por meio do programa Praat. Resultados: os resultados apontam para mudanças ocorridas no uso das pausas, em função do estilo de narrativa. Conclusão: as pausas, em estilos de programas interativos de televisão têm o papel de construir turnos de fala.

DESCRITORES: Fala; Narração; Jornalismo; Televisão

\section{INTRODUÇÃO}

A classificação das pausas varia quanto a sua natureza e função ${ }^{1-4}$ e possuem duração (longas/breves), localização e distribuição diferenciadas.

De acordo com sua função, as pausas podem ser classificadas em: delimitativas, expressivas, de planejamento discursivo e de estruturação discursiva. As pausas que têm função delimitativa demarcam os constituintes da frase, tais como: palavras, grupos de palavras ou frases. As pausas expressivas ou enfáticas desempenham a função de destacar palavras que o falante deseja ressaltar. As pausas de planejamento discursivo são utilizadas pelos falantes para planejar a continuidade de sua fala, e as pausas de estruturação discursiva são utilizadas para organizar partes do discurso como, por exemplo, a introdução ou o fechamento de uma palestra ${ }^{5-7}$.

De acordo com a sua natureza ou tipo, as pausas também podem ser classificadas em: silenciosas, quando realmente há um silêncio; preenchidas ou de planejamento, quando há um alongamento da vogal, lembrando uma idéia; e perceptivas, quando sinalizam por meio de uma variação de f0 ou uma ruptura no fluxo da fala ${ }^{8-10}$.

O uso das pausas na língua falada é diferente da língua escrita. O profissional que utiliza estas duas

(1) Fonoaudióloga; Presidente da ONG Vez da Voz; Especialista em Voz pelo Centro de Estudos da Voz; Mestra em Fonoaudiologia; Doutoranda em Lingüística pelo Laboratório Integrado de Análise Acústica, da Pontifícia Universidade Católica de São Paulo. línguas é o jornalista de televisão, que procura ter uma boa performance vocal perante o telespectador. Respeitar a leitura das pausas da língua escrita no momento televisivo, onde é usada a língua falada pode gerar artificialidade na entoação e prejudicar a performance do falante. Pode-se considerar que a própria língua delimita o uso da expressividade.

Na língua escrita, as pausas são representadas pelos sinais de pontuação, e desempenham uma função lingüística na construção de sentido, agem sobre a sintaxe, a semântica e hierarquizam os diferentes discursos ${ }^{11}$. É comum dizer que a vírgula indica a pausa que se faz na leitura para respirar. A vírgula assinala a inversão da ordem direta da frase, a intercalação de elementos que interrompem a leitura do enunciado, a omissão de certos elementos subentendidos ou a ênfase ${ }^{12}$. Sua principal função é a de estruturar o pensamento.

Os sinais não estão na mesma situação das letras, não são representantes gráficos da cadeia falada, já que sua função delimitativa abrange não apenas a dimensão fônica, mas também a dimensão semântica da palavra. Portanto, não é aconselhável seguir os sinais de pontuação da escrita na fala.

Na escrita, a pontuação desempenha papel de articulador textual desencadeando coesão. As vírgulas acabam por articular partes, estabelecendo relações entre idéias, assuntos e intensificando conteúdos ${ }^{13}$.

Na língua falada, as pausas atuam no campo da expressividade, variando conforme o estilo. Delimitam idéias, estruturam o pensamento e auxiliam o jogo melódico da entoação, que é rítmica e funciona 
como suporte indispensável para a compreensão do que é construído por meio das palavras ${ }^{11}$.

É importante ressaltar que os textos de televisão são escritos e lidos no teleprompter, aparelho que reproduz o texto jornalístico, possibilitando assim, sua leitura. Portanto, no momento do telejornal e demais programas de televisão relacionados ao jornalismo ocorre a interação entre as duas línguas: a escrita e a falada. Vale destacar que a fala é feita para o outro, buscando-se sempre uma adequada compreensão da mensagem.

Em análises sobre narrações de televisão no decorrer do tempo, pode-se observar mudanças na maneira como os apresentadores e jornalistas utilizam os recursos prosódicos. O uso da pausa nas narrações, em diferentes estilos de televisão, também passou por este processo e sofreu modificações quanto o seu uso ${ }^{14-16}$.

Mais de 40 anos se passaram desde que o primeiro telejornal foi ao ar e a leitura de textos nas apresentações orais sofreram modificações quanto à maneira como o locutor atribui proeminências, varia a taxa de elocução e distribui as pausas, transmitindo suas marcas pessoais e variações refletidas nacultura, na mentalidade coletiva e em uma expressividade única.

As narrações de televisão, sejam telejornais ou programas interativos, baseiam-se em sua maioria, na leitura de textos, que antigamente eram escritos pelos responsáveis (diretores, editores) dos programas e, atualmente, são escritos pelo próprio apresentador. Este fato faz uma enorme diferença para o profissional que interpreta o texto, pois é mais fácil interpretar um texto escrito pelo próprio autor, do que escrito por outra pessoa. Como autor, há mais possibilidades de interpretação e de buscar um estilo próprio, ser responsável pelos recursos fônicos ${ }^{17}$. Portanto, para que o falante assuma suas interpretações e estas lhe sejam genuínas, é preciso que ele também seja o escritor, dono de seu próprio texto.

O embasamento teórico deste estudo é feito à luz da Lingüística, que se propõe a estudar a língua, e nos discursos individuais analisa os elementos vocais e sua organização.

Durante a narração de um jornalista, seqüências de fala e pausa ajudam o ouvinte a organizar o pensamento e entender as informações, segundo relata a autora ${ }^{2}$ em seus estudos embasados na fonéticaacústica, o qual comparou a fala de profissionais durante a notícia da TV, na leitura e fala espontânea. Os achados demonstraram que no uso profissional, pausas silenciosas são usadas para programar uma informação já conhecida e são muito usadas pelos jornalistas de televisão.

Já as pausas preenchidas, segundo a autora ${ }^{2}$, são índices da complexidade do planejamento verbal e utilizadas mais na fala espontânea, funcionando como indicadores temporais de um discurso não-preparado. No uso profissional, pausas preenchidas diminuem a fluência da fala. Relata ainda que a fala profissional -é diferente de outros estilos do próprio sujeito e conclui que na fala do telejornal há mais formalidade, os discursos são pré-preparados, tendem a parecer espontâneos e são produzidos em situações não-interativas. A taxa de elocução é mais rápida, sem hesitações para transmitir o maior número de informações em um tempo controlado.

Na língua falada, a combinação dos elementos vocais e o encadeamento das pausas atuarão para estruturar o pensamento, disciplinar, ordenar, clarificar e definir rupturas sintáticas da língua ${ }^{4,18}$.

A pausa pode ser utilizada para separar as unidades melódicas ${ }^{6}$. Na fala, a entoação organiza-se em unidades, que são os segmentos melódicos, formados por grupos de intensidade, que podem variar de uma palavra monossilábica a um conjunto de cerca de quinze sílabas.

A pausa na escrita ${ }^{8}$, representada pela vírgula separa os sujeitos de seus atributos, os complementos, as orações principais coordenadas, as orações subordinadas, os apostos, vocativos, conjunções, o pronome relativo "que", dentre outros elementos. Algumas gramáticas e artigos ${ }^{19-25}$ apontam como principal a função das vírgulas sendo separador de constituintes. Os autores ${ }^{26,27}$ descrevem os sinais de pontuação e indicam dois tipos de pausas: conclusas (ponto, ponto e vírgula, interrogação e exclamação) e inconclusas (vírgula, dois pontos, reticências). Já este outro autor ${ }^{23}$ classifica a pontuação em dois pontos, interrogação, exclamação, etc, e pausas, como: vírgula, ponto e vírgula, ponto final.

A pontuação é definida como o emprego de sinais convencionais para indicar na escrita as diferentes pausas ou inflexões de voz ${ }^{28}$. Também distingue a pontuação das palavras, frases e textos e classifica em: separadores, pausais e semânticos ${ }^{29}$. Aponta para a organização sintática da pausa e sua correspondência com o oral, não sendo pontual, mas contínua, afetando assim, toda uma frase ou um segmento de frase. E também para a função semântica da pausa que pode completar ou suprir as unidades da primeira articulação, as morfológicas, as lexicais ou as sintáticas.

A pausa, como qualquer palavra ocorre em um contexto ${ }^{30}$. É importante destacar que o uso das pausas, quando contextualizadas dentro de uma estrutura sintática tem a possibilidade de adquirir significados diferentes, que podem realçar a importância da continuidade sonora, ou podem atuar como um signo, ou seja, um mistério, uma dúvida,morte ou expectativa. Mas deve estar contextualizado para que não seja interpretado como uma falha ou um ruído ${ }^{10}$. Na língua falada ${ }^{3}$, 
o contínuo da elocução é cortado por pausas que não correspondem, senão ocasionalmente, à separação mental que fazemos das palavras.

As pausas silenciosas ${ }^{28}$, ou melhor, o silêncio se apresenta sempre da mesma forma, isto é, a ausência de som, mas sua ocorrência pode ter interpretações diferentes, dependendo do contexto social ou cultural. As pausas, quando bem utilizadas podem destacar uma informação e criar expectativa no ouvinte.

O jornalismo moderno não só noticia o fato ${ }^{31}$, mas interpreta-o e o uso das pausas certamente está ligado a uma escala de valores expressivos. Há palavras fundamentais ${ }^{32,33}$, que levam em si toda a responsabilidade do sentido da frase, encarregadas de estabelecer conexão entre as idéias, como; substantivos, adjetivos, verbos e às vezes, advérbios ou numerais.

O interesse em realizar esta pesquisa surgiu em assessorias fonoaudiológicas aos repórteres de televisão e na observação quanto à mudança nas leituras dos textos com o decorrer do tempo, antes mais formais, com obediência às regras escritas da língua como ao respeito às vírgulas do texto e, hoje, mais informais, reproduzindo a expressividade da fala espontânea.

O objetivo desta pesquisa foi analisar o uso da pausa silenciosa em narrações de estilos diferentes de televisão, tanto na língua escrita quanto na língua falada, e demonstrar que conforme sua utilização pode auxiliar ou prejudicar a inteligibilidade de uma informação.

\section{MÉTODOS}

Neste estudo foram analisadas gravações antigas e atuais, coletadas da TV, com dois jornalistas (1 e 2 ) experientes em televisão. As gravações compreendem quatro tipos de programas: passagem de reportagens, narração por telefone, apresentação em estúdio e programa interativo ao vivo.

Esta análise é um recorte do que ocorre na expressividade da fala. Nesta pesquisa, voltou-se apenas para o uso das pausas silenciosas. Durante a fala, sabe-se que outros fenômenos ocorrem com relação aos parâmetros vocais, mas não serão estudados neste momento.

As amostras de fala do jornalista 1 correspondem a matérias realizadas nas seguintes datas e situações: passagem (1988), informação por telefone (1991), e um programa interativo ao vivo (2006).

As amostras de fala do jornalista 2 correspondem a gravações realizadas em estúdio, em duas épocas diferentes, sendo uma apresentação de telejornal (1980) e um programa jornalístico (2006).

Estes arquivos de som foram submetidos à análise-acústica, utilizando o programa de análise de fala Praat, desenvolvido por Paul Boersma e David
Weenink, do Instituto de Ciência-Fonética da Universidade de Amsterdã ${ }^{34}$. Foi realizada a segmentação e medida a duração em milisegundos (ms) das pausas silenciosas e dos grupos de frases delimitadas por elas, como é demonstrado na Figura 1.

Para facilitar a visualização, após a segmentação, as frases foram separadas em grupos em torno de 10 segundos para a elaboração de Figuras e Tabelas.

Foram analisadas as distribuições das pausas, suas categorias e funções de acordo com a seguinte classificação: pausa de delimitação, que separa constituintes das frases; pausa de expressividade, que destaca algum elemento e produz um efeito; pausa de planejamento discursivo, que organiza a seqüência da frase; pausa de respiração, que tem uma razão fisiológica e pausa de estruturação discursiva.

Neste trabalho, foram consideradas pausas silenciosas breves as que apresentaram medição entre 50 e $250 \mathrm{~ms}$ e se houvesse um elemento oclusivo junto com a pausa, e só foram consideradas pausas as que estiveram acima de $200 \mathrm{~ms}$, segundo critério do autor ${ }^{35}$. As pausas silenciosas longas foram aquelas que apresentaram mais de $250 \mathrm{~ms}$.

O tempo de narração foi apresentado entre chaves \{\} , antes da frase narrada e o tempo de silêncio e a porcentagem em relação ao tempo de fala foram apresentados entre parênteses ( ) depois da frase.

Os enunciados foram classificados de acordo com a tipologia gramatical, feita na análise sintática, após os parênteses ( ), em cada enunciado.

Ao final dos textos narrados por um jornalista, foram escritos comentários sobre como cada profissional lidou com as pausas em narrações de naturezas diferenciadas. Foi realizada uma análise qualitativa sobre o uso das pausas por cada apresentador nas diferentes amostras de fala.

\section{RESULTADOS}

Apresenta-se, a seguir, cinco amostras de fala de dois jornalistas em estilos de narrações diferenciadas. Há o texto de narração na íntegra, seguido de divisões em enunciados, efetuadas pelos referidos sujeitos por meio de pausas silenciosas.

Indica-se, como apontado na metodologia, a duração total dos enunciados (entre chaves) e a duração das pausas (entre parênteses). Na análise dessas amostras, aborda-se os aspectos sintáticos e a classificação tipológica e funcional das pausas.

No primeiro texto, o jornalista 1 narra em 18 segundos uma passagem, caracteriza-se pelo aparecimento da imagem do repórter em atuação como correspondente internacional em um incêndio, em Portugal, no ano de 1988.

Texto 1 na íntegra:

Quase quinze horas depois do início do incêndio e algumas labaredas insistem em arder. Os bombei- 
ros lutam contra a pior calamidade que Lisboa enfrentou desde o terremoto de 1755, mas é uma luta perdida. Séculos de história estão reduzidos à fumaça e cinzas.

\section{Resultado da análise:}

\{2580ms\} Quase quinze horas depois do início do incêndio/ (183ms; 7\%) - adjunto -adverbial de modo;adv.tempo;

$\{2050 \mathrm{~ms}\}$ algumas labaredas insistem em arder/ (478ms;23\%) - final de oração complexa;

$\{3240 \mathrm{~ms}\}$ Os bombeiros lutam contra a pior calamidade que Lisboa enfrentou/ (331ms; 10\%);

$\{2770 \mathrm{~ms}\}$ desde o terremoto de 1755/

(391ms;14\%) - adjunto adverbial de tempo;

$\{1160 \mathrm{~ms}\}$ mas é uma luta perdida/ (475ms; $41 \%)$ - oração coordenada adversativa;

\{1060ms\} Séculos de história/ (258ms; 24\%)sintagma nominal - sujeito;

\{1550ms $\}$ estão reduzidos à fumaça/ (340ms; $22 \%$ ) - predicado.

$\{1310 \mathrm{~ms}\}$ e cinzas.

No texto 2, o jornalista 1 narra ao vivo, por telefone, na atuação como correspondente internacional no Kwait durante 12 segundos, em 1991.

Texto 2 na íntegra:

Um ano depois da invasão que sacudiu o mundo o Kwait é de fato um país diante de sua própria imagem à procura de uma nova identidade. A luta pela libertação criou a sede da liberdade.

\section{Resultado da análise:}

(2780ms) Um ano depois da invasão que sacudiu o mundo/ (83ms, 3\%) - adjunto adverbial de tempo;

(1254ms) o Kwait é de fato/ (84ms, 7\%) - adjunto adverbial de modo;

(2293ms) um país diante de sua própria imagem/ (55ms, 2\%) - adjunto adverbial de modo;

(1862ms) à procura de uma nova identidade/ (490ms, 26\%).

(463ms) Aluta/ (86ms, 19\%) - núcleo do sintagma nominal;

(851ms) pela libertação/ (367ms, 43\%) - frase preposicional - modificador;

(1546ms) criou a sede da liberdade.

No texto 3, o jornalista 1 narra ao vivo um programa de entretenimento, durante 12 segundos, em 2006.

Texto na íntegra:

E quem será que a rainha Mara vai mandar pro paredão?

Agora, vamos ver se essa turma aproveitou a festa de ontem. Melhor do que o violão sonífero de Gustavo deve ter sido.

Análise dos resultados:

(670ms) E quem será/ (371ms, 55\%) - oração principal

(2170ms) que a rainha Mara vai mandar pro paredão/ (768ms, 35\%) oração subordinada;

(343ms) Agora/ (257ms, $75 \%$ ) adjunto adverbial de tempo;

(812ms) vamos ver/ (175ms, $22 \%)$ sintagma verbal / oração principal;

(3430ms) se essa turma aproveitou a festa de ontem/ (319ms, 9\%) oração subordinada;

(3460ms) melhor do que o violão sonífero de Gustavo deve ter sido/ oração subordinada.

No texto 4 , o jornalista 2 narra um telejornal por 61 segundos, em 1980.

Texto na íntegra:

E atenção o conselho de segurança das nações unidas acaba de decidir: o secretário geral da ONU Javier Pérez de Cuéllar vai fazer ainda esta noite um último apelo de paz ao homem forte do Iraque Saddam Hussen em nome de toda a comunidade internacional.

A rádio Bagdá informou esta noite que Saddam Hussen fez hoje uma visita às tropas iraquianas que estão no Kwait desde agosto.

O homem forte do Iraque disse que suas tropas estão prontas para a guerra.

O presidente da comissão francesa de assuntos exteriores que esteve em Bagdá há poucos dias disse agora há pouco em Paris que Saddam Hussen pode cometer um gesto teatral e anunciar a qualquer momento a retirada das tropas iraquianas do Kwait.

Nós voltaremos a qualquer momento com as últimas informações sobre a ameaça de guerra no Golfo. Nossos repórteres nos Estados Unidos, na Europa, na Jordânia e em Israel acompanham todos os lances da crise.

\section{Resultado da análise:}

(4500ms) E atenção o conselho de segurança das nações unidas acaba de decidir/ (471ms, $10 \%)$ oração complexa;

(2860ms) O secretário geral da ONU Javier Pérez de Cuéllar/ (379ms, 13\%) - sujeito;

(5600ms) vai fazer ainda esta noite um último apelo de paz ao homem forte do Iraque Saddam Hussen/ (277ms, 5\%) - predicado;

(2900ms) em nome de toda a comunidade internacional/ (505ms, 17\%) final de oração simples;

(1010ms) A rádio Bagdá/ (263ms, 26\%) sujeito;

(6320ms) informou esta noite que Saddam Hussen fez hoje uma visita às tropas iraquianas que estão no Kwait desde agosto/ (536ms, 8\%) final de oração complexa;

(1340ms) o homem forte do Iraque/ (375ms, 28\%) sujeito;

(2780ms) disse que suas tropas estão prontas para a guerra/ (502ms, 18\%) predicado / final de oração simples;

(4960ms) O presidente da comissão francesa de 
assuntos exteriores que esteve em Bagdá há poucos dias/ (424ms, 9\%) sujeito;

(1570ms) disse agora há pouco em Paris/ (308ms, $20 \%$ ) adjunto adverbial de tempo;

(1090ms) que Saddam Hussen/ (410ms, 38\%) oração subordinada;

(2130ms) pode cometer um gesto teatral/ (307ms, $14 \%$ ) final de oração complexa.

(5040ms) anunciar a qualquer momento a retirada das tropas

iraquianas do Kwait/ (2220ms, 44\% ) oração coordenada;

(4750ms) Nós voltaremos a qualquer momento com as últimas informações sobre a ameaça de guerra no Golfo/ (641ms, 13\%) oração simples;

(4140ms) Nossos repórteres nos Estados Unidos, na Europa, na Jordânia e em Israel/ (403ms, 10\%) sujeito;

(2570ms) acompanham todos os lances da crise - predicado / final da oração simples.

No texto 5 , o jornalista 2 narra um programa jornalístico por 53 segundos, em 2006.

Texto na íntegra:

Boa Noite. Sexta-feira de carnaval. Em todo o país milhões de pessoas se preparam para um teste de resistência. Dançar, pular, brincar durante quatro dias.

Um bom momento para lembrar: oito entre dez brasileiros enfrentam a famosa dor nas costas, e podem ter problemas de coluna em dias de tanta agitação.

Nesta noite vamos rever quem investiga, como se movimenta a nossa espinha dorsal.

Salto alto, prejudica ou ajuda? Quanto deve pesar a mochila das crianças?

Qual a melhor posição para os trabalhos domésticos mais comuns?

Afinal, o que você pode fazer pela sua coluna?

\section{Resultado da análise:}

(851ms) Boa Noite/ (768ms, 90\%) sintagma nominal; (2200ms) Sexta-feira de carnaval/ (65ms, 3\%) sintagma nominal; (4980ms) Em todo o país milhões de pessoas se preparam para um teste de resistência/ (660ms, 13\%) oração simples;

(505ms) Dançar/ (177ms, 35\%) sintagma verbal; (352ms) Pular/ (550ms, 156\%) sintagma verbal;

(2220ms) Brincar durante quatro dias/ (537ms, $24 \%$ ) sintagma verbal / final da oração coordenada;

(1560ms) Um bom momento para lembrar/ (504ms, $32 \%$ ) sintagma nominal;

(446ms) Oito/ (191ms, 43\%) advérbio de tempo / sintagma nominal;

(1570ms) entre dez brasileiros/ (338ms, 22\%) sintagma preposicional;

(2750ms) enfrentam a famosa dor nas costas/ (411ms,15\%) sintagma verbal;

(2220ms) E podem ter problemas de coluna/ (442ms, 20\%) oração coordenada;

(1950ms) em dias de tanta agitação/ (1070ms, $55 \%$ ) sintagma preposicional;

(934ms) Nesta noite/ (315ms, 34\%) sintagma preposicional;

(1490ms) vamos rever/ (290ms, 19\%) sintagma verbal;

(4170ms) quem investiga como se movimenta a nossa espinha dorsal/ (931ms, 22\%) oração complexa;

(977ms) Salto alto/ (406ms, 42\%) sintagma nominal;

(1320ms) Prejudica ou ajuda?/ (713ms, 54\%) oração coordenada;

(2840ms) Quanto deve pesar a mochila das crianças?/ (715ms, $25 \%$ ) oração simples;

(4270ms) Qual a melhor posição para os trabaIhos domésticos mais comuns?/ (1210ms, 28\%) oração simples;

(414ms) Afinal/ (621ms, 150\%) sintagma

preposicional;

(2100ms) o que você pode fazer/ (421ms, 20\%) sintagma verbal;

(1330ms) pela sua coluna? Sintagma preposicional / final de oração complexa.

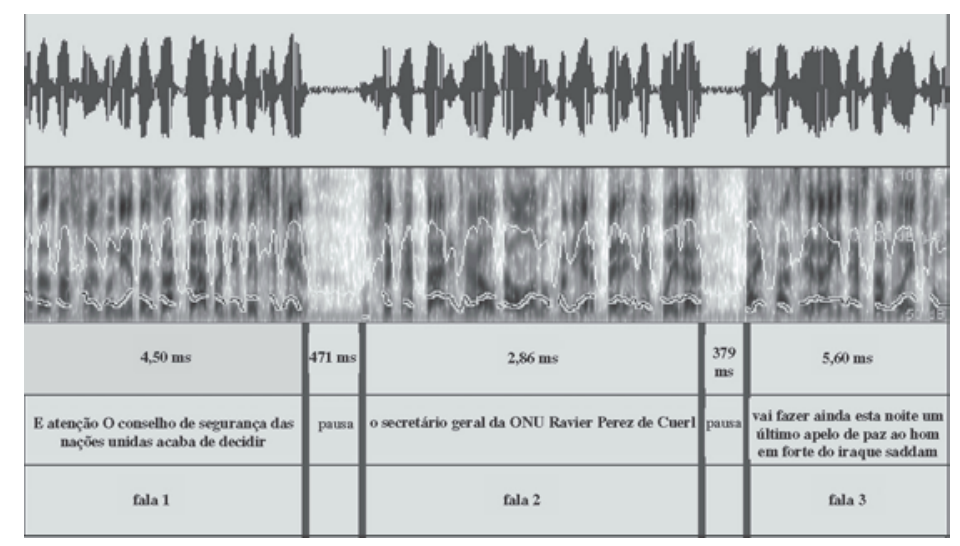

Figura 1- Análise demonstra pausas silenciosas no meio dos enunciados na narração do jornalista 2 (1980), em apresentação de telejornal 


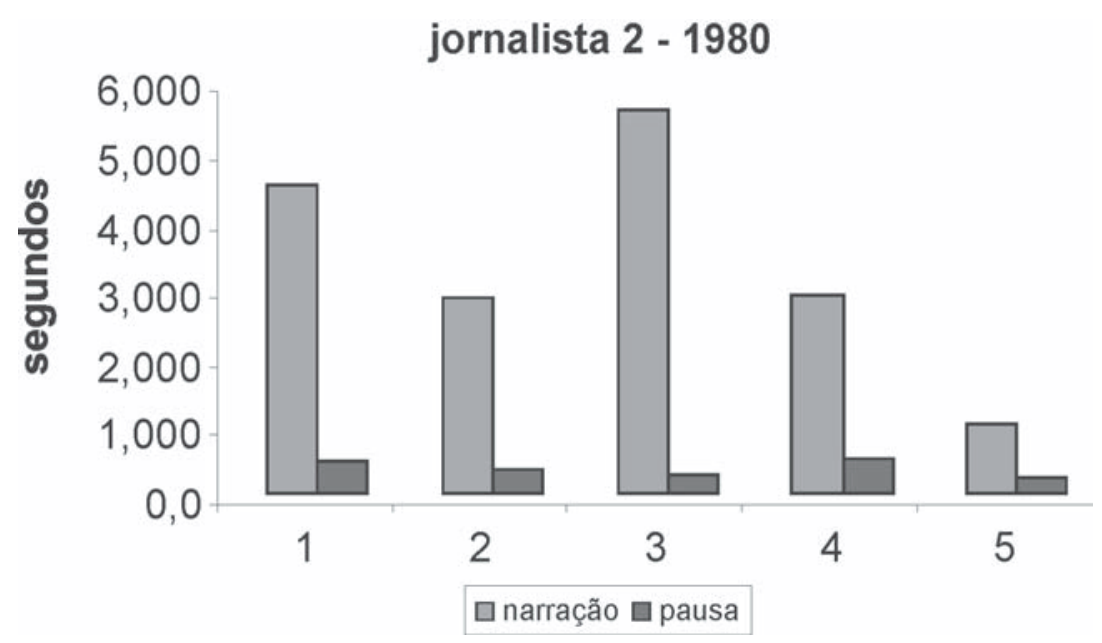

Figura 2 - Duração das pausas e dos enunciados na narração do jornalista 2 (1980)

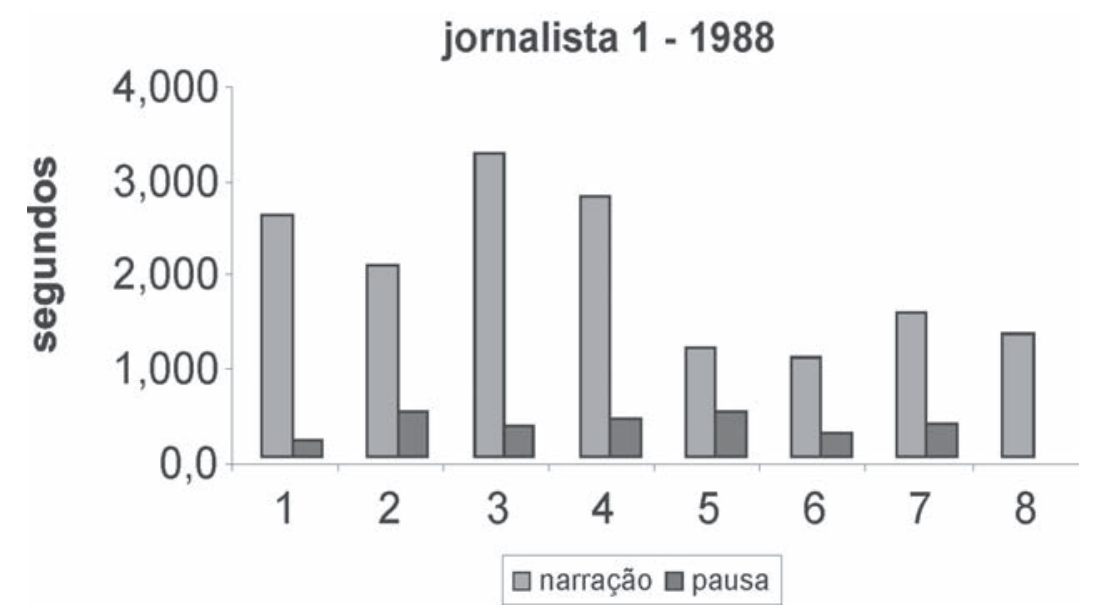

Figura 3 - Duração das pausas e dos enunciados na narração do jornalista 1 ao narrar uma passagem

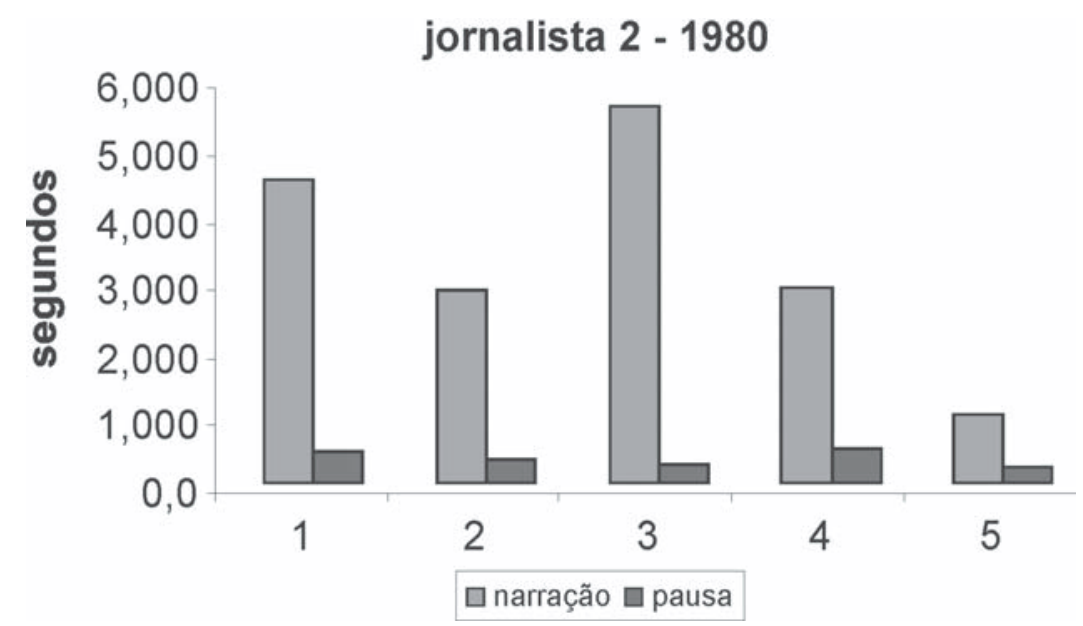

Figura 4 - Duração das pausas e dos enunciados na narração do jornalista 1, em locução por telefone 


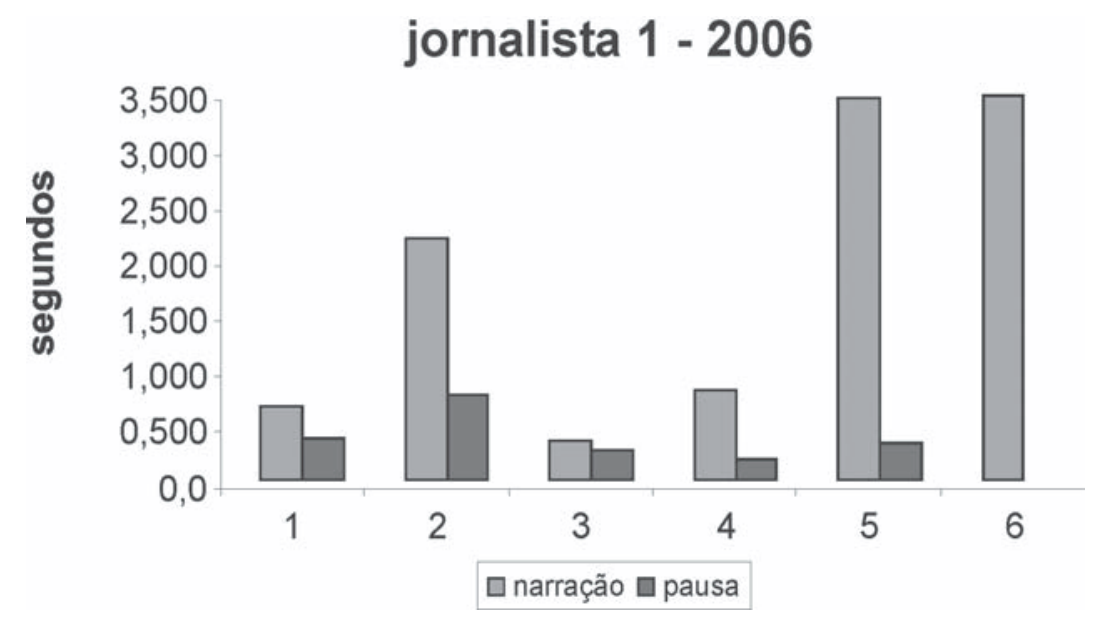

Figura 5 - Duração das pausas e dos enunciados do jornalista 1 em narração ao vivo, em um programa de entretenimento

\section{DISCUSSÃO}

No texto 1, a pausa é utilizada com duas funções: delimitativa e enfática. As pausas delimitativas; separam constituintes como orações e sujeito e duram um tempo maior do que as que separam adjuntos adverbiais. A pausa enfática ocorre antes de uma preposição que liga dois substantivos, conferindo proeminência ao último deles. Apesar da duração da pausa enfática ser menor do que as delimitativas, ao comparar-se a relação entre o tempo de silêncio e o tempo de fala, verifica-se que a pausa silenciosa corresponde a $20 \%$ do tempo de fala, enquanto nas pausas delimitativas finais chegam a corresponder $40 \%$. As pausas que separam os adjuntos adverbiais refletem interações com aspectos sintáticos e semântico-pragmáticos. A menor pausa deste texto ocorre após o adjunto adverbial de tempo que se encontra no início da oração. O deslocamento desse constituinte para o início da frase, por si só destaca o conteúdo. A maior pausa intra-segmento ocorre dentro de uma oração adjetiva restritiva. Observa-se que o apresentador optou por colocar a pausa separando a oração adjetiva. A distribuição da pausa após o advérbio de tempo também destaca este constituinte que apresenta informação relevante para a compreensão do fato.

Estes autores ${ }^{5,7,10,11,19,35}$ afirmam que pausas enfáticas destacam palavras que o falante deseja ressaltar, bem como auxiliam na organização do discurso. $\mathrm{O}$ uso das pausas, neste caso, assume um efeito explicativo.

No texto 2, também as pausas finais e a intermediária, de natureza enfática são longas. As demais pausas intermediárias, apresentam alterações de duração em relação às pausas intermediárias do texto 1 , revelando uma mudança estilística. A pausa enfática final representa $43 \%$ do tempo de fala, enquanto que as delimitativas representam até $20 \%$ do tempo de fala. A pausa enfática produzida pelo apresentador conduz à interpretação do telespectador 19,30,36. Segundo o autor, contar uma história todo mundo conta ${ }^{37}$. Contar bem, todo mundo pode. Então, o papel da narração no telejornalismo não é apenas informar sobre os acontecimentos, mas mostrá-los de modo a prender o interesse de quem ouve a informação. As pausas finais, quando bem utilizadas valorizam uma informação e ajudam na estruturação do pensamento, e conseqüentemente, quando presentes, auxiliam no entendimento da mensagem.

O jornalismo não só noticia o fato ${ }^{31}$, mas interpreta-o e o uso das pausas certamente está ligado a uma escala de valores expressivos. Portanto, são recursos estilísticos que podem e devem ser utilizados.

No texto 3, as pausas exercem uma função discursiva, de estruturação de uma conversa imaginária entre o locutor e o telespectador, dando-lhe a oportunidade de estruturar o pensamento e participar deste "diálogo" televisivo. Nesse sentido, o apresentador cria, com o uso das pausas mais freqüentes e longas, enunciados de durações diferentes, que se coadunam com as características de um programa interativo e criam espaços para a voz participativa do telespectador. Com exceção do último enunciado, que se caracteriza como um comentário por parte do apresentador, todos os demais enunciados são dirigidos ao interlocutor, quer seja em forma de pergunta ou de expressões fáticas. Com o avanço da tecnologia e mudanças sociais que promovem a interação, o uso das pausas foi modificado pelos narradores de televisão e marca, hoje, novos estilos ${ }^{14,19,31}$. O enunciado que resulta de uma escolha dos meios de expressão do falante é que determina um estilo ${ }^{20}$, também entendido como a qualidade do enunciado, entre os ele- 
mentos de uma língua. Para este autor ${ }^{26}$, o melhor exemplo de estilos de pontuar está nos textos jornalísticos. Essas e outras concepções estilísticas são abordadas criticamente nestes trabalhos ${ }^{5,18,30}$, e embora tragam uma contribuição importante para a conceituação do estilo e das pausas pelo fato de adotarem a noção de escolha, não contemplam o trabalho ativo do indivíduo com a forma e o conteúdo.

Vale ressaltar que o estilo de fala e o uso das pausas são feitos para o outro e sempre pretender causar um efeito de sentido. Fala-se e pausa-se para o outro.

No texto 4, os enunciados são longos variando a duração entre 1 e 6 segundos intercalados por pausas. Pausas silenciosas são maiores que 500 ms. Há pausas depois de substantivos próprios, destacando-os. Também ocorrem pausas antes e depois de verbos. Depois do nome próprio há pausas enfáticas que destacam o substantivo. $\mathrm{O}$ uso das pausas neste texto segue muito a sintaxe, e o texto apresenta característica informativa. A mudança de assunto é apresentada inter-segmento pela maior pausa da narração, com $44 \%$ em relação ao tempo de fala, enquanto que as outras permanecem em torno de $15 \%$.

$\mathrm{O}$ fato deste texto ser mais antigo demonstra o quanto a língua escrita influenciou na narração de TV. Havia muito rigor quanto ao fato de seguir as regras. Segundo este Manual, de $1987^{16}$ um texto jornalístico, além de relatar um contexto, deve ser claro e completo. Cada frase deve conter uma idéia e o uso da terceira pessoa é obrigatório porque o jornalista testemunha um fato e não é o personagem principal. Ao anteceder no tempo, pode-se encontrar na literatura que com o advento da imprensa, começou a ocorrer a utilização da pausa articulada à oralidade, tendo a função de esclarecimento. Desde então, as marcações de pausa não cessaram de evoluir e de regularizar seu emprego segundo várias normas. A pausa na escrita ${ }^{8}$, representada pela vírgula, separa os sujeitos de seus atributos, os complementos, as orações principais coordenadas, as orações subordinadas, os apostos, vocativos, conjunções, o pronome relativo "que", dentre outros elementos.

Portanto, é nítida a relação do uso das pausas aos textos escritos, em telejornais mais antigos.

O texto 5 é marcado por enunciados curtos, palavras isoladas com tempos de pausas maiores de 400 $\mathrm{ms}$. A menor pausa marca um tempo de $65 \mathrm{~ms}, 3 \%$ do tempo de fala; as maiores pausas ocorrem após enunciados interrogativos, que possibilitam ao ouvinte a elaboração de uma resposta, e variam de 25 a $150 \%$ do tempo de fala. A variação dos valores nos tempos das pausas e os enunciados curtos criam o diálogo e mudanças de turno entre o apresentador e o telespectador. A pausa colocada após um sintagma nominal e seguida de uma interrogativa faz com que o telespectador tenha tempo de pensar no tema e conseqüentemente de responder a pergunta. São estratégias mais utilizadas na fala espontânea.

Estes achados corroboram os de alguns autores ${ }^{11,19,36}$, que afirmam que pelo estudo dos indicadores da estruturação temporal da fala, como: tempo de pausas silenciosas e preenchidas é possível definir estratégias para diferentes estilos de discursos, em diferentes grupos de profissionais.

Neste estudo, o uso das pausas pelos repórteres mostrou-se diferenciado em relação à natureza do programa e à função da pausa inter ou intra enunciados.

As pausas de maior duração foram utilizadas nos programas de natureza interativa. Esse tipo de pausa foi utilizado pelo repórter como uma estratégia para dar voz ao telespectador e possibilitar, dessa maneira, a criação de um diálogo. O tempo de pausa representa, nesse diálogo, o turno do telespectador.

Observa-se também que a duração das pausas variou de acordo com as funções delimitativas e enfáticas. As pausas delimitativas variaram em duração de acordo com o uso dos constituintes sintáticos. Houve pausas mais longas entre frases do que entre sintagmas. As pausas delimitativas entre sintagmas apresentaram menor duração do que as pausas enfáticas nos mesmos contextos.

Constata-se que o estilo de telejornal apresentou as menores porcentagens de pausa em relação ao tempo de fala e os programas interativos, os maiores. Programas mais formais tendem a seguir mais a sintaxe, respeitando assim, as regras da língua escrita.

Vale ressaltar que o uso da língua e dos parâmetros vocais depende do contexto, que delimita o uso das pausas, sua distribuição e funções. Portanto cabe ao repórter ter consciência do lugar do emprego da pausa e de como a palavra é dita.

Este estudo é importante para subsidiar o trabaIho de assessoria fonoaudiológica e esclarecer o entendimento do uso das pausas e suas funções em diferentes estilos de narrações em programas de televisão. Afinal, o fonoaudiólogo é o profissional que orienta os repórteres no uso de estratégias eficazes para a comunicação oral durante as narrações.

\section{CONCLUSÃO}

Observou-se que o uso da pausa silenciosa varia de acordo com o estilo do programa de televisão, apresentando gradiência quanto à produtividade e a distribuição. Foi menos produtiva, ou seja, menos freqüente, no estilo de apresentação de telejornal, que se aproxima da leitura em voz alta, do que na de passagem, que geralmente apóia-se em texto decorado. As pausas silenciosas foram mais freqüentes no estilo de programa interativo, que se aproxima do diálogo. 
A distribuição das pausas também diferiu nos três estilos de textos, separando constituintes maiores, como as frases, na apresentação do telejornal, e incluindo constituintes menores, tais como palavras e sintagmas nos textos mais interativos. A pausa, entre outros elementos prosódicos, é fundamental para a construção da expressividade oral, por desem- penhar um papel delimitativo e sinalizador de efeitos de sentido.

\section{AGRADECIMENTOS}

À Profa. Dra. Sandra Madureira pela dedicação neste trabalho e ao apoio financeiro do CNPq.

\section{ABSTRACT}

Purpose: this study aims at investigating the distribution and functions of silent pauses in oral discourse, particularly in narratives of TV programs with differentiated nature. Methods: for this study, speech samples of two journalists from five TV programs were selected. The analyses were based on phoneticacoustic analysis and the time of narrative and silent pauses was measured in milliseconds (ms) by means of PRAAT speech analysis program. Results: the results indicate that the use of pauses vary according to the style of the narrative. Conclusion: terminal pauses are longer than intermediate pauses, which respect the higher order constituents (subject/predicate).

KEYWORDS: Speech; Narration; Journalism; Television

\section{REFERÊNCIAS}

1. Behlau M, Rehder MI. Higiene vocal para o canto coral. Rio de Janeiro: Revinter; 1997.

2. Martins NS. Introdução à estilística. 2. ed. São Paulo: T.A. Queiroz; 1997.

3. Camara Junior M. Contribuição à estilística portuguesa. 3. ed. Rio de Janeiro: Ao Livro Técnico; 1973. 4. Olívia MM. Aspectos língüísticos da pontuação. Rev Port. 1959; 24(Série A).

5. Madureira S. O sentido do Som. [doutorado]. São Paulo (SP): Pontifícia Universidade Católica de São Paulo; 1992.

6. Marcuschi LA. Análise da conversação. 5. ed.São Paulo: Ática; 2003.

7. Camara Junior M. Manual de expressão oral e escrita. 2. ed. Rio de Janeiro: J. Ozon; 1966.

8. Passos A. A arte de pontuar. Rio de Janeiro: Pongetti; 1959.

9. Torres AA. Da pontuação. In: Moderna gramática expositiva da língua portuguesa. 16. ed. São Paulo: Fundo de Cultura; 1966.

10. Silva JLOA. Rádio: oralidade mediatizada: o spot e os elementos da linguagem radiofônica. [mestrado]. São Paulo (SP): Pontifícia Universidade Católica de São Paulo; 1997.

11. Chacon L. Ritmo da escrita: uma organização do heterogêneo da linguagem. São Paulo: Martins Fontes; 1998.

12. Camargo TN. Uso da vírgula. São Paulo: Manole; 2005.

13. Correa MLG. Pontuação: sobre seu ensino e concepção. Leitura: teoria e prática. v. 24. 1994. p. $52-65$.

14. Erbolato MM. Técnicas de codificação em jorna- lismo. 5. ed. São Paulo: Ática; 1991.

15. Elias M. Discursos geopolíticos da mídia: jornalismo e imaginário internacional na América Latina. [doutorado]. São Paulo (SP): Pontifícia Universidade Católica de São Paulo; 2003.

16. Folha de São Paulo. Manual geral de redações. 2. ed. São Paulo: Folha de São Paulo; 1987.

17. Goffman E. The lecture: forms of talk. University of Pensilvania; 1981.

18. Paschoal MS, Zanotto. Comportamento da função estilística no nível fonológico. [doutorado]. São Paulo (SP): Pontifícia Universidade Católica de São Paulo; 1975.

19. Martins DMR, Freitas MJ. Estruturas temporais da fala: lendo notícias na TV. In: Fonética do português: 30 anos de investigação. Lisboa: Caminho; 2002.

20. Guiraud P. Aestilítica. São Paulo: Mestre Jou; 1970.

21. Lyons J. Linguagem e língua: uma introdução. Rio de Janeiro: LTC; 1987.

22. Bagno $\mathrm{M}$. Português ou brasileiro? um convite à pesquisa. 5. ed. São Paulo: Parábola; 2005.

23. Cegalla DP. Novíssima gramática. São Paulo: Nacional; 1977.

24. Camara Junior M. Dispersos. Rio de Janeiro: Fundação Getúlio Vargas; 1972.

25. Bechara E. Moderna gramática portuguesa. 20. ed. São Paulo: Nacional; 1988.

26. Rocha ILV. Aquisição da pontuação: usos e saberes de crianças na escrita de narrativas. [doutorado]. São Paulo (SP): Pontifícia Universidade Católica de São Paulo; 1994.

27. Bechara E. Moderna gramática portuguesa: cursos de $1^{\circ}$ e $2^{\circ}$ graus. 22. ed. São Paulo: Nacional; 1977. 
28. Steinberg M. Os elementos não-verbais da conversação. São Paulo: Atual; 1988.

29. Catach. Les dictionnaires de l'Académie française, 1994. HWP B.21, publ. septembre 1996. Editors of CHWP 1996. [Publication originale in $\mathrm{CCH}$ Working Papers, 4 (1994) et Dictionnairique et lexicographie, 3 (1995).

30. Possenti S. Discurso, estilo e subjetividade. [doutorado]. Campinas (SP): Universidade Estadual de Campinas; 1986.

31. Dittrich IJ. Linguística e jornalismo: dos sentidos à argumentação. Cascavel: Edunioeste; 2003.

32. Lapa MR. Estilística da língua portuguesa. 7. ed.
Rio de Janeiro: Livraria Acadêmica; 1973.

33. Bally C. El lenguaje y la vida. Buenos Aires: Losada; 1941.

34. Programa computadorizado gratuito de análiseacústica fala Praat. Disponível em: URL: www.praat.org 35. Laver J, Trudgill P. Phonetics and linguistic marlers in speech. In: Scherer K, Giles H. Social markers in speech. London: Cambridge University Press; 1980. 36. Granger GG. Filosofia do estilo. São Paulo: Perspectiva; 1974.

37. Minchillo CA, Cabral I. A narração. 5. ed. São Paulo: Atual; 1989.

RECEBIDO EM: 15/09/2006

ACEITO EM: 05/06/2007

Endereço para correspondência:

R. Alvorada, 735 ap. 41

São Paulo - SP

CEP: $04550-003$

Tel.: (11) 38489751 / (19) 91130404 / (11) 76678267

E-mail: claudiacotes@uol.com.br 